\title{
Understanding and reconstructing the coastal sea level variations along the western boundary of the North Pacific
}

Penghui $\mathrm{Li}^{1}$ and Fanghua $\mathrm{Xu} \mathrm{u}^{1,2^{*}}$

\begin{abstract}
To better understand the coastal sea level (SL) variations along the western boundary of the North Pacific, we quantitatively estimate the contributions of various forcing to the coastal SL variations on seasonal and longer time scales. Based on a western boundary SL theory and a linear least-squares regression, we obtain a polynomial equation to estimate the coastal SL variations from ocean interior information, atmospheric forcing, as well as local steric effects. The estimated results can explain about 91\% (93\%) of the SL variations at tide gauges south (north) of the Kuroshio extension jet. It is found that the local thermosteric effect is dominant on seasonal time scales. On interannual time scales, the signals from ocean interior and atmospheric forcing are dominant. For decadal SL trends, the coastal SL rise is mainly resulted from the signals from the open ocean. With the same polynomial equation, the SL variations at 6 new tide gauges were estimated and compared to the nearest satellite measurements. The newly estimated SL is generally in much better agreement with the tide gauge data than the satellite data. It is promising to apply the newly derived polynomial equation to estimate SL variations along the western boundary of the North Pacific where tide gauge data are not available. Particularly, the approach is promising to estimate the future SL change given the required oceanic and atmospheric conditions.
\end{abstract}

Keywords: Sea level variability, Rossby wave, Coastal-trapped waves, Western boundary, North Pacific

\section{Introduction}

The coast of the western boundary of the North Pacific, with a series of islands and large population (Anthoff et al. 2006), is under the direct threat of SL rise. Understanding and reconstructing the coastal SL variations along the western boundary of the North Pacific are greatly desired.

Many studies have investigated the dynamical causes of regional SL variability along the western boundary of the North Pacific. The SL variability on short time scales is under the direct influence of tides, local winds and sea level pressure (SLP). The situation might be changed for

\footnotetext{
*Correspondence: fxu@tsinghua.edu.cn

${ }^{1}$ Ministry of Education Key Laboratory for Earth System Modeling, and Department of Earth System Science, Tsinghua University, Beijing 100084, China

Full list of author information is available at the end of the article
}

much longer time scales because short-term fluctuations could be averaged out. Wang et al. (2016) pointed out that the local wind field and SLP have a nonnegligible impact on the coastal sea level anomalies on seasonal time scales. Cui et al. (1995) indicated SLP variations over the eastern North Pacific could influence SL along Japan on decadal time scales. Zhang and Ichikawa (2005) found that the SL along the south coast of Japan is negatively correlated with Kuroshio velocity on time scales longer than a few months. Ishii et al. (2006) indicated that the thermosteric effects could induce large variations of local SL along the Japanese coast. Yasuda and Sakurai (2006) proposed that the bi-decadal variability of SL along Japan coast results from linear long Rossby wave from the North Pacific. While Sasaki et al. (2014) argued that the jet-trapped Rossby wave along the Kuroshio extension (KE) plays a major role on SL variability on decadal time 
scales. Jet-trapped Rossby wave concentrated onto the KE jet could produce higher SL variability south of the $\mathrm{KE}$, because Kelvin and coastal-trapped waves propagate southward along the coast. While north of the KE, the influence of linear long Rossby wave is weak, and results in lower SL variability.

Many factors affect the SL variability along the western boundary of the North Pacific, such as the interior SL variations, sea surface wind, sea level pressure, upstream Kuroshio transport and local steric effects, as revealed by the aforementioned studies. However, we do not yet have a clear quantification of SL change induced by these factors. In this study, we quantitatively estimate the contributions of these factors to the SL change in the south and north of the KE jet separately. The local steric effects are closely related to the ocean heat and salt content, and are primarily resulted from the surface heat and freshwater flux. In shallow places along the coastlines, the water is well mixed. Changes in sea surface temperature (SST) and sea surface salinity (SSS) are close to changes in the mean values of temperature and salinity in shallow seas, and subsequently proportional to changes in thermosteric and halosteric effects, respectively (Ezer 2019). The surface heat and freshwater flux are not explicitly included in the analysis.

Moreover, we aim to obtain a simple relation to estimate coastal SL variations from interior ocean SL, atmosphere information, local SST and SSS. Generally, there are two kinds of datasets used to study SL, tide gauge data and satellite altimeter data (Douglas 1992; Peltier 2001; Wang et al. 2003). The satellite altimeter data cover a wide range, but the data accuracy is questionable along coastlines (Cipollini et al. 2018). As for the tide gauge data, measurements of SL in tide gauges can be traced back to 1900s, but the distribution of tide gauges is relatively sparse (Woodworth and Player 2003). And the data availability is intermittent. Due to the limitation of the tide gauge data and satellite altimeter data, we reconstructed SL variability along the coast of the western North Pacific from ocean interior SL information, atmospheric forcing, SST, SSS, as well as Kuroshio transport, based on a theory proposed by Minobe et al. (2017) and a simple linear regression. The results are in good agreement with the independent tide gauge data. So, we are confident to get a more accurate estimate of SL change in coastal regions without tide gauges with the new method.

\section{Data and methods \\ Data}

This study used the monthly 'Revised Local Reference' (RLR) data from 19 tide gauges along the western boundary of the North Pacific (markers in Fig. 1) over the period of 1993-2018, downloaded from the Permanent

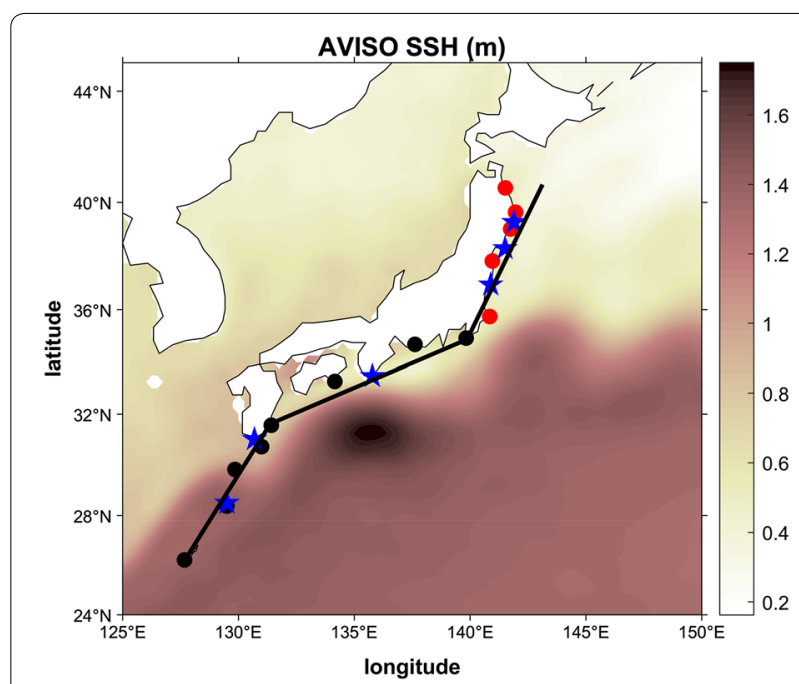

Fig. 1 The tide gauge stations south (black dots) and north (red dots) of the KE jet superimposed with mean sea surface height (SSH) from AVISO from 1993 to 2018. The black lines represent the alignment of alongshore wind. The six blue stars denote the tide gauge stations for sea level tests

Table 1 Tide gauges' locations along the western boundary of the North Pacific

\begin{tabular}{llllll}
\hline Station & Lat $\left({ }^{\circ} \mathbf{N}\right)$ & Lon $\left({ }^{\circ} \mathrm{E}\right)$ & Station & Lat $\left({ }^{\circ} \mathbf{N}\right)$ & Lon $\left({ }^{\circ} \mathrm{E}\right)$ \\
\hline NAHA & 26.22 & 127.67 & OFUNATO II & 39.02 & 141.75 \\
NAZE & 28.38 & 129.50 & MIYAKO II & 39.64 & 141.96 \\
NAKANOS & 29.83 & 129.85 & HACHINOHE II & 40.53 & 141.52 \\
NISHINOO & 30.73 & 131.00 & NASE III & 28.50 & 129.50 \\
ABURATSU & 31.57 & 131.42 & ODOMARI & 31.02 & 130.69 \\
MUROTOMI- & 33.27 & 134.16 & KUSHIMOT & 33.47 & 135.78 \\
$\quad$ SAKI & & & & & \\
MAISAKA & 34.68 & 137.62 & ONAHAMA & 36.94 & 140.89 \\
MERA & 34.92 & 139.83 & AYUKAWA & 38.30 & 141.51 \\
CHOSHIGYOKO & 35.74 & 140.85 & KAMAISI II & 39.27 & 141.89 \\
SOMA & 37.83 & 140.96 & & & \\
\hline
\end{tabular}

Service for Mean Sea Level (PSMSL, http://www.psmsl .org). The data are not corrected for land movement because of the large uncertainties in land movement correction techniques (Woodworth and Player 2003). Even though, the data are good for long-term analysis of sea level as introduced in Church et al. (2001). The details about station names, latitudes and longitudes are listed in Table 1. The reference level of the RLR data is available from the individual tide gauge station pages. SL data at 13 out of 19 tide gauges are used to obtain the relation of SL with various forcing, while SL data at the other 6 are used to evaluate the reconstructed SL from the newly derived relation. The six stations are selected to represent 
the locations from low to high latitudes along the coasts of the North Pacific. In addition, since there is a remarkable SL rise at the data record of tide gauges north of the KE due to Japan 2011 earthquake and Tsunami $\left(38.1^{\circ} \mathrm{N}\right.$, $142.6^{\circ} \mathrm{E}$ ), we only consider the time period from 1993 to 2011. The data after 2011 are not long enough for longterm analysis and are not discussed hereafter.

The global SL used in this study is produced by SSALTO/DUACS and downloaded from AVISO (http:// www.aviso.altimetry.fr) with $0.25^{\circ} \times 0.25^{\circ}$ horizontal resolution from 1993 to 2018 . The $0.25^{\circ} \times 0.25^{\circ}$ monthly $10-\mathrm{m}$ wind and sea level pressure over the same period is obtained from the ERA5 Reanalysis (https://cds.clima te.copernicus.eu). The Kuroshio transport is estimated along an upstream section at $24^{\circ} \mathrm{N}$ from the Simple Ocean Data Assimilation (SODA3) reanalysis, downloaded from http://dsrs.atmos.umd.edu/DATA/soda3/. SST and SSS are obtained from EN4 quality-controlled subsurface ocean temperature and salinity profiles, downloaded from https://www.metoffice.gov.uk/hadobs/ en $4 /$.

\section{Method}

Minobe et al. (2017) proposed a theory to predict coastal SL variability along a curved western boundary based on ocean interior SL variability. The theory (Minobe et al. 2017) is developed from Godfrey (1975), which indicated that western boundary SL differences at two particular latitudes are proportional to the incident mass induced by long Rossby wave traveling into the western boundary. According to Minobe et al. (2017), if the time scale considered is much longer than the time required for long Rossby wave crossing the western boundary width, the $\mathrm{SL}$ anomalies along the western boundary $\left(\mathrm{SLA}_{0}\right)$ can be estimated as

$$
\mathrm{SLA}_{0}=\frac{f(y)}{f\left(y_{\mathrm{p}}\right)} h\left[X_{\mathrm{w}}\left(y_{\mathrm{p}}\right), y_{\mathrm{p}}, t\right]+f(y) \int_{y}^{y_{\mathrm{p}}} \frac{\beta}{f^{2}} h\left[X_{I}\left(y^{\prime}\right), y^{\prime}, t\right] \mathrm{d} y^{\prime}
$$

where $y$ and $y_{p}$ are respectively the particular latitude and higher latitude, $f$ is the Coriolis parameter, $\beta$ is the rate of change of $f$ with latitude, $h$ is the sea level, and $X_{\mathrm{W}}\left(X_{I}\right)$ is the western end of the western boundary current (ocean interior). This equation considers that the sea level variability at a particular latitude along the western boundary is the sum of the contributions from ocean interior information propagated by long Rossby wave between that latitude and higher latitude (the 2nd term on the right-hand side of Eq. 1), and from the western boundary sea level at the higher latitude by Kelvin waves or coastal-trapped waves (the 1st term on the right-hand side of Eq. 1). To fulfill the requirement of the time for long Rossby wave crossing the western boundary (about 10-20 days), we only consider SL variations on seasonal and longer time scales.

To quantitatively investigate the contributions from each factor, we regressed SLA from tide gauge stations onto $\mathrm{SLA}_{0}$ (representing signals from ocean interior), onshore wind anomalies (OWA), alongshore wind anomalies (AWA), sea level pressure anomalies (SLPA) and Kuroshio transport anomalies (KTA), as well as SST anomalies (SSTA) and SSS anomalies (SSSA) along the western boundary of the North Pacific. Each factor is normalized by its absolute mean value. A polynomial equation is obtained as follows,

$$
\begin{aligned}
y= & a \times \mathrm{SLA}_{0}+b \times \mathrm{OWA}+c \times \mathrm{AWA}+d \times \mathrm{SLPA} \\
& +e \times \mathrm{SSTA}+f \times \mathrm{SSSA}+g \times \mathrm{KTA}
\end{aligned}
$$

where $a, b, c, d, e, f$ and $g$ are regressed coefficients, and $y$ is the reconstructed SLA. The regression coefficients at different seasons are listed in Table 2 (Table 3) south (north) of the KE jet.

\section{Results and discussion}

\section{Quantification of coastal SL variability}

The coastal SL at 13 tide gauge stations is highest in summer and lowest in winter (dots in Fig. 2). We first estimate coastal SL variations induced by ocean interior signals $\left(\mathrm{SLA}_{0}\right)$ at various seasons from Eq. 1. In spring, the estimated $\mathrm{SLA}_{0}$ is in good agreement with SLA from the tide gauge stations, indicating that the signals from ocean interior are important for the coastal SL change (Fig. 2a). On the other hand, the estimated SLA 0

Table 2 Coefficients of linear regression of normalized SLA, OWA, AWA, SLPA, SSTA, SSSA and KTA south of the KE jet

\begin{tabular}{llclllrr}
\hline Season & $\mathbf{S L A}_{\mathbf{0}}(\boldsymbol{a})$ & OWA $(\boldsymbol{b})$ & AWA $(\boldsymbol{c})$ & SLPA $(\boldsymbol{d})$ & SSTA $(\boldsymbol{e})$ & SSSA $(\boldsymbol{f})$ & KTA $(\boldsymbol{g})$ \\
\hline Spring & 0.36 & -0.07 & -0.09 & -0.46 & 0.40 & -0.19 & -0.05 \\
Summer & 0.35 & 0.29 & -0.08 & -0.25 & 0.26 & -0.16 & 0.10 \\
Autumn & 0.39 & 0.18 & -0.14 & -0.61 & 0.04 & -0.03 & 0.06 \\
Winter & 0.35 & 0.21 & -0.25 & -0.65 & 0.43 & -0.08 & -0.04 \\
\hline
\end{tabular}


Table 3 Coefficients of linear regression of normalized SLA, OWA, AWA, SLPA, SSTA and SSSA north of the KE jet

\begin{tabular}{lllllll}
\hline Season & $\mathbf{S L A}_{\mathbf{0}}(\boldsymbol{a})$ & OWA $(\boldsymbol{b})$ & AWA $(\boldsymbol{c})$ & SLPA $(\boldsymbol{d})$ & SSTA $(\boldsymbol{e})$ & SSSA $(\boldsymbol{f})$ \\
\hline Spring & 0.32 & -0.26 & -0.17 & -0.42 & 0.80 & -0.14 \\
Summer & 0.38 & -0.45 & -0.04 & -0.34 & 0.62 & -0.13 \\
Autumn & 0.60 & -0.12 & -0.10 & -0.32 & 0.22 & -0.09 \\
Winter & 0.42 & -0.12 & -0.08 & -0.43 & 0.64 & -0.16 \\
\hline
\end{tabular}

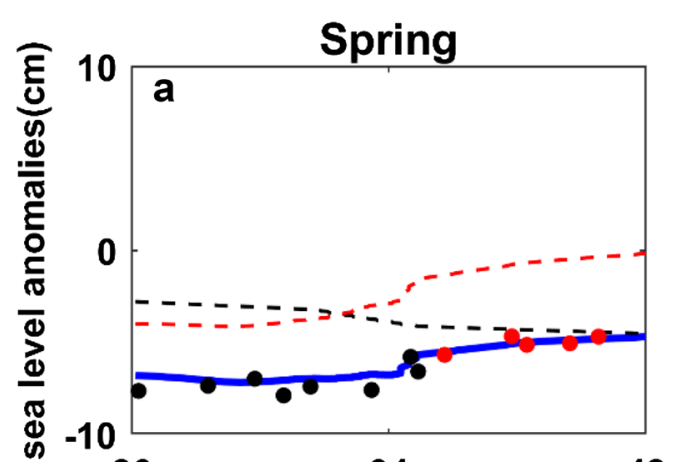

26

34

42

latitude $\left({ }^{\circ} \mathrm{N}\right)$

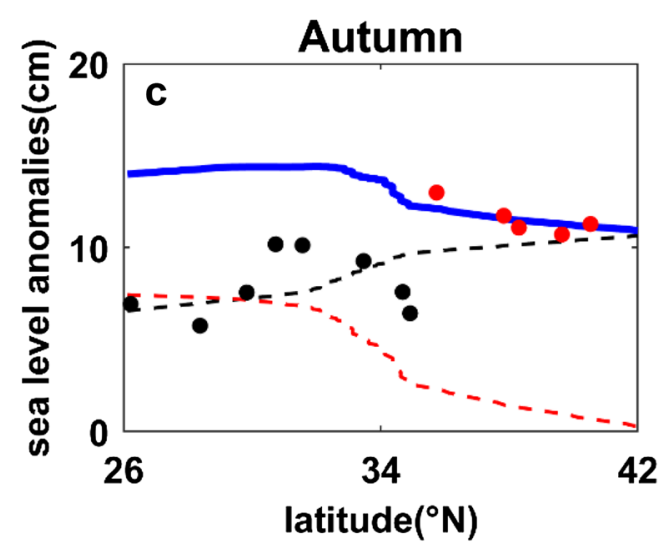

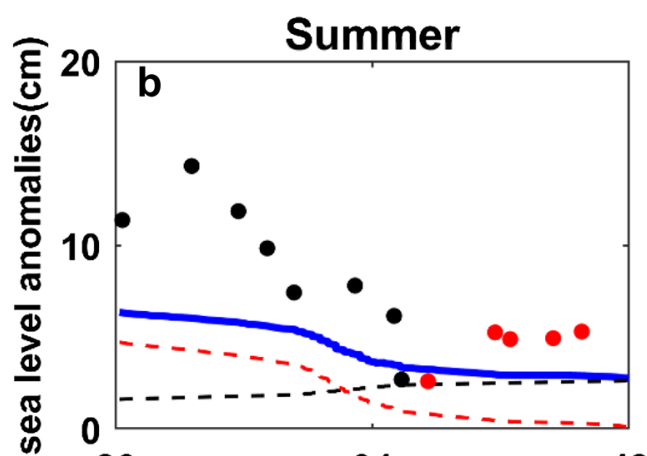

34

42

latitude $\left({ }^{\circ} \mathrm{N}\right)$

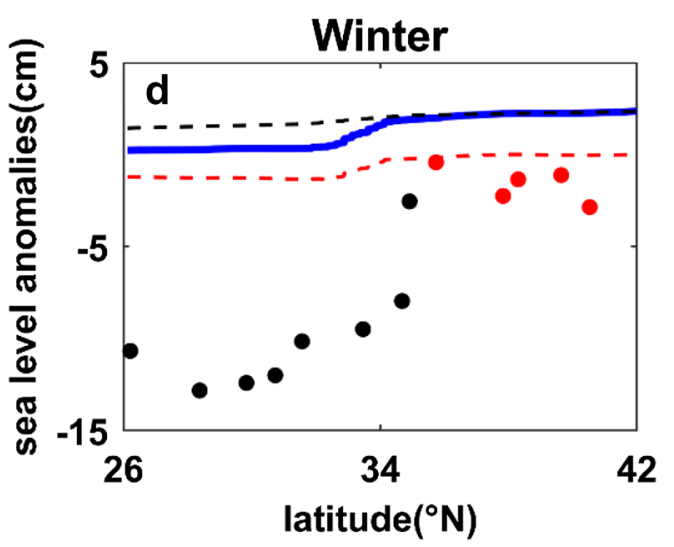

Fig. 2 Comparison of the estimated SLA from Eq. 1 (blue) and the SLA from eight tide gauges (black dots) south of the KE and from five tide gauges (red dots) north of the KE in spring (March, April and May), summer (June, July, and August), autumn (September, October, and November) and winter (December, January and February). The black dash lines represent the contributions from coastal-trapped waves (the 1st term on the right-hand side of Eq. 1), while the red dash lines represent the contributions from the long Rossby waves (the 2nd term on the right side of Eq. 1)

is lower (higher) than SLA from tide gauges in summer (in autumn and winter), suggesting that there are other important factors. Furthermore, the magnitude of the coastal-trapped wave term of Eq. 1 (black dash lines in Fig. 2) is always larger than that of the long Rossby wave (red dash lines in Fig. 2) north of the KE jet, whereas the situation is mostly reversed south of the KE jet. These results indicate that the long Rossby wave (the coastal-trapped waves) plays an important role on SLA $_{0}$ south (north) of the KE jet, consistent with the separation of 'active zone' and 'shadow zone' caused by the jet-trapped Rossby wave (Sasaki et al. 2014). For stations near the KE jet, the dominant signals vary with seasons, probably due to the meridional migration of the KE jet or active Eddy activities (Qiu et al. 2015).

Figure 3 shows the distribution of surface wind and SLP in four seasons. The onshore wind direction is northwestward perpendicular to the coastal lines (black lines in Fig. 1), while the alongshore wind direction is northeastward direction along the coastal line. In spring, there is weak westerly (Fig. 3a), which in summer becomes much stronger southeasterly accompanied by minimum SLP over the ocean (Fig. 3b). The monsoonal wind becomes weak northwesterly in autumn (Fig. 3c) and strong 


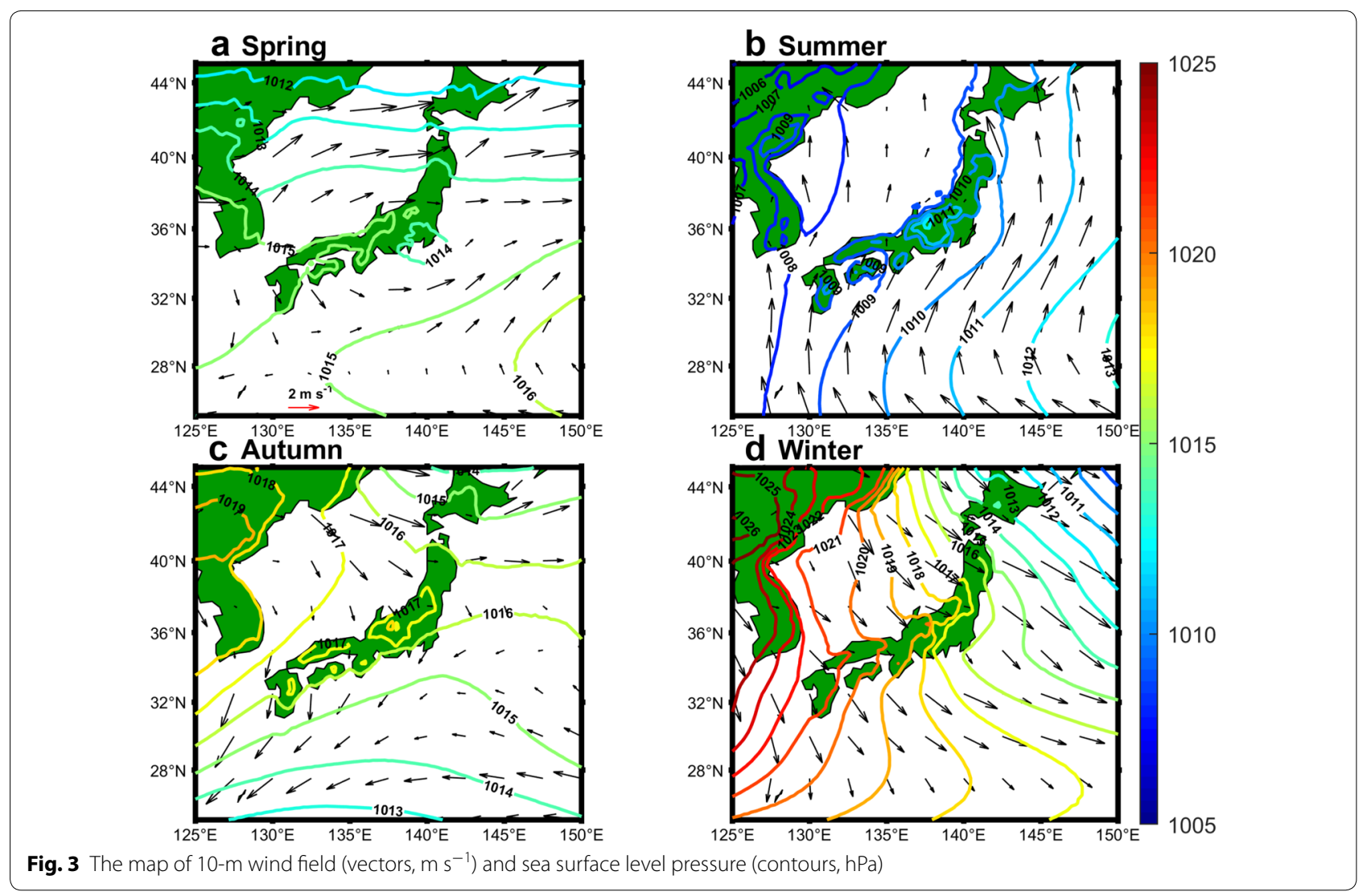

northwesterly in winter with maximum SLP (Fig. 3d). Figure 4 (Fig. 5) shows the time series of each factor averaged over the nearest grid to the tide gauge stations from the datasets described in "Data" section.

On seasonal time scales, signals from ocean interior $(a)$, SLP $(d)$ and thermosteric effect $(e)$ are the top three factors affecting SL variations (Tables 2,3). South of the $\mathrm{KE}$ jet, the effects of wind vary seasonally. In spring, coefficients of OWA $(b)$ and AWA $(c)$ are small, consistent with a weak wind field (Fig. 3a). While $b$ becomes larger in other seasons, leading to a higher (lower) SLA in summer (winter), in accordance with onshore (offshore) wind in Fig. 3b (Fig. 3d). Note that $f$ and $g$ are relatively small, which indicate the halosteric effect and Kuroshio transport effect are small. North of the KE jet, the coefficient $e$ is generally larger than other coefficients, which indicates that the local thermosteric effect has a more important impact on the coastal SL fluctuations. Noticeably, unlike the OWA in the south of KE jet, $b$ becomes negative, probably due to the close relation between SST and the wind. If SST and SSS are not considered in the regression, the coefficient $b$ becomes positive.

To get the contributions of each factor on interannual and longer time scales, we calculate the regression coefficients after 1-year low pass of each factor. The results are shown in Table 4. The local thermosteric effects are small on these time scales. The effects from ocean dynamical processes $(a)$ and onshore wind $(b)$ are primarily dominant south of the KE jet, while oceanic processes $(a)$ and SLP $(d)$ are dominant north of the KE jet. The results indicate that ocean dynamical processes and atmospheric forcing are dominant over coastal SL variations on interannual time scales. Moreover, the $\mathrm{SLA}_{0}$ is in better agreement with the SLA north of the KE jet than south of the KE jet (Fig. 2), consistent with higher coefficient of SLA $(a=0.59)$ in the north than in the south $(a=0.46)$. Since the magnitude of the coastal-trapped wave signal is much larger than that of the long Rossby wave (close to zero, Fig. 2) north of the KE, the coastal SL variability is mainly dominated by coastal-trapped waves, consistent with the findings in Sasaki et al. (2014).

With the polynomial equation, we compare the reconstructed SLA $(y)$ with the SLA from the tide gauge stations and the results are shown in Fig. 6. South of KE jet, the squared correlation $\left(R^{2}\right)$ between the reconstructed SLA and the SLA from the 8 tide gauge stations (black dots in Fig. 1) on a monthly basis is 0.91 with a $P$ value less than 0.01 (Fig. 6a). The sea level rising trend is about $3.4 \pm 0.3 \mathrm{~mm}$ year ${ }^{-1}$ from tide gauge measurements and $3.0 \pm 0.3 \mathrm{~mm}_{\text {year }}{ }^{-1}$ from 


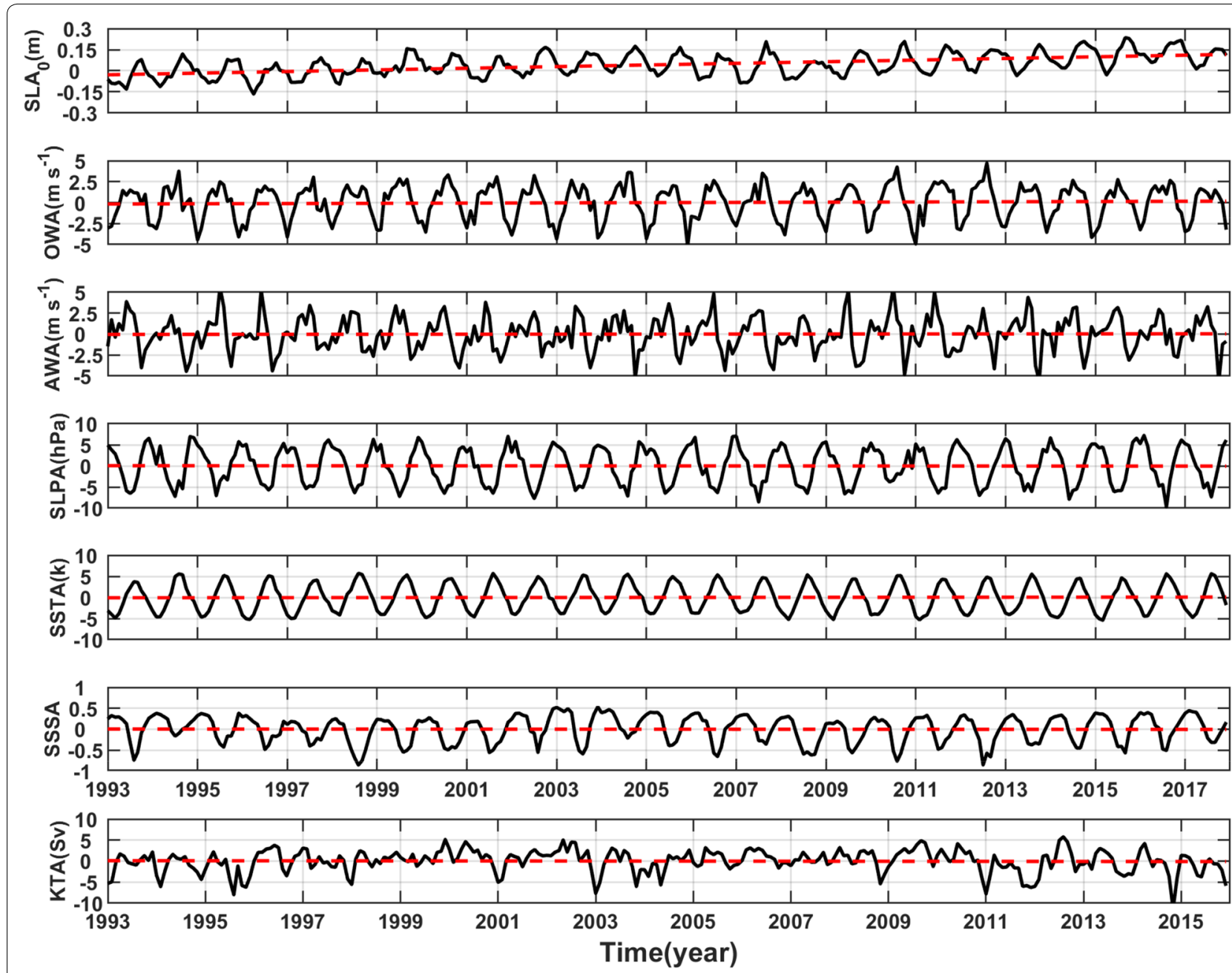

Fig. 4 The time series of averaged SLA, OWA, AWA, SLPA, SSTA, SSSA and KTA south of the Kuroshio extension. The red dash lines denote the linear trend over the period

the regressed results. The SL rising trend is consistent with previous studies (e.g., Qiu et al. 2015). After the long-term trend is removed, the $R^{2}$ remains to be about 0.91 (Fig. 6b). Noteworthy, only $\mathrm{SLA}_{0}$ has a clear rising trend, while the trends of other factors are close to zero (Fig. 4). This indicates that the coastal SL rising trend mainly results from oceanic interior signals. After 1-year low pass of the detrended data, the $R^{2}$ is about 0.70 (Fig. 6b), indicating the $70 \%$ coastal SL variability on interannual time scale is captured by the simple regression method. While north of the KE jet, the $R^{2}$ of the reconstructed SLA and the SLA from the five tide gauges (red dots in Fig. 1) is 0.93 (0.93) before (after) the long-term trend is removed (Fig. 6c, d). The sea level rising trends from tide gauge measurements are $4.2 \pm 0.3 \mathrm{~mm}$ year $^{-1}$ and the regressed results are
$3.2 \pm 0.5 \mathrm{~mm}$ year $^{-1}$. Furthermore, the $R^{2}$ remains high (0.86) after 1-year low pass (Fig. 6d).

\section{Coastal SL reconstruction}

We also attempt to use the simple regression method to reconstruct coastal SL when tide gauges are missing. To evaluate the coastal SLA reconstruction, we chose the SL measurements from three new stations south of the $\mathrm{KE}$ jet and three new stations north of the KE jet (blue stars in Fig. 1) for comparison. With the seasonal coefficients in Tables 2 and 3, the SL variations in these new stations were reconstructed and compared with the observed SLA from the tide gauges (Fig. 7). The correlation coefficients and root mean square errors (RMSE) were calculated. The nearest AVSIO SLAs to the six new tide gauges were used for comparison. From Fig. 7a, b, 


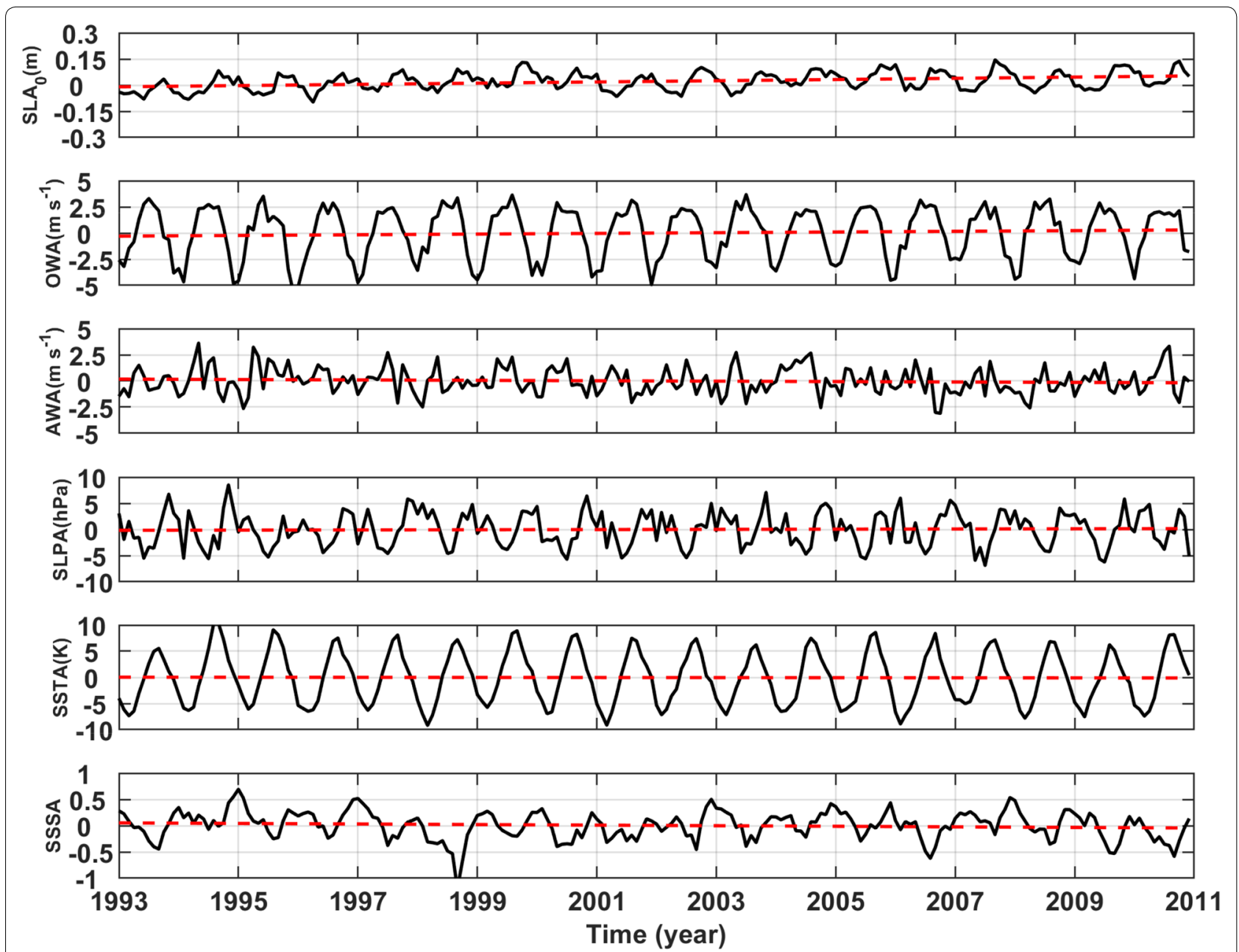

Fig. 5 The time series of averaged SLA, OWA, AWA, SLPA, SSTA and SSSA north of the Kuroshio extension. The red dash lines denote the linear trend over the period

Table 4 Coefficients of linear regression of normalized SLA, OWA, AWA, SLPA, SSTA, SSSA and KTA after 1-year low pass

\begin{tabular}{llllclll}
\hline & SLA $_{\mathbf{0}}(\boldsymbol{a})$ & OWA $(\boldsymbol{b})$ & AWA $(\boldsymbol{c})$ & SLPA $(\boldsymbol{d})$ & SSTA $(\boldsymbol{e})$ & SSSA $(\boldsymbol{f})$ & KTA $(\boldsymbol{g})$ \\
\hline South & 0.46 & 0.60 & -0.02 & 0.12 & 0.11 & -0.11 & 0.04 \\
North & 0.59 & 0.24 & -0.08 & -0.48 & 0.03 & -0.18 & \\
\hline
\end{tabular}

the reconstructed SLA has higher $R^{2}$ and lower RMSE than AVISO SLA except at NASE III station (the southernmost blue star in Fig. 1), indicating that the reconstruction of coastal SL could provide a good estimation of SLA along the western boundary of the North Pacific. The good performance of AVISO data is expected since NASE III is mainly surrounded by open water, where the quality of AVISO data is high. Noteworthy, the comparison is done after the removal of trends for all datasets.
With trends, the correlation coefficients $\left(R^{2}\right)$ are further enhanced and the values of RMSE remain the same.

The six tide gauges used to evaluate the equations are close to the ones used to build the equations. To check whether the sea level (SL) features at these tide gauge stations are similar, we calculate the correlation coefficients of the sea level at six tide gauge stations with the ones used to build the equation. South of the KE jet, the correlation coefficient $\left(R^{2}\right)$ is about 0.34 on average, much lower than the values we obtained (Fig. 7a). 


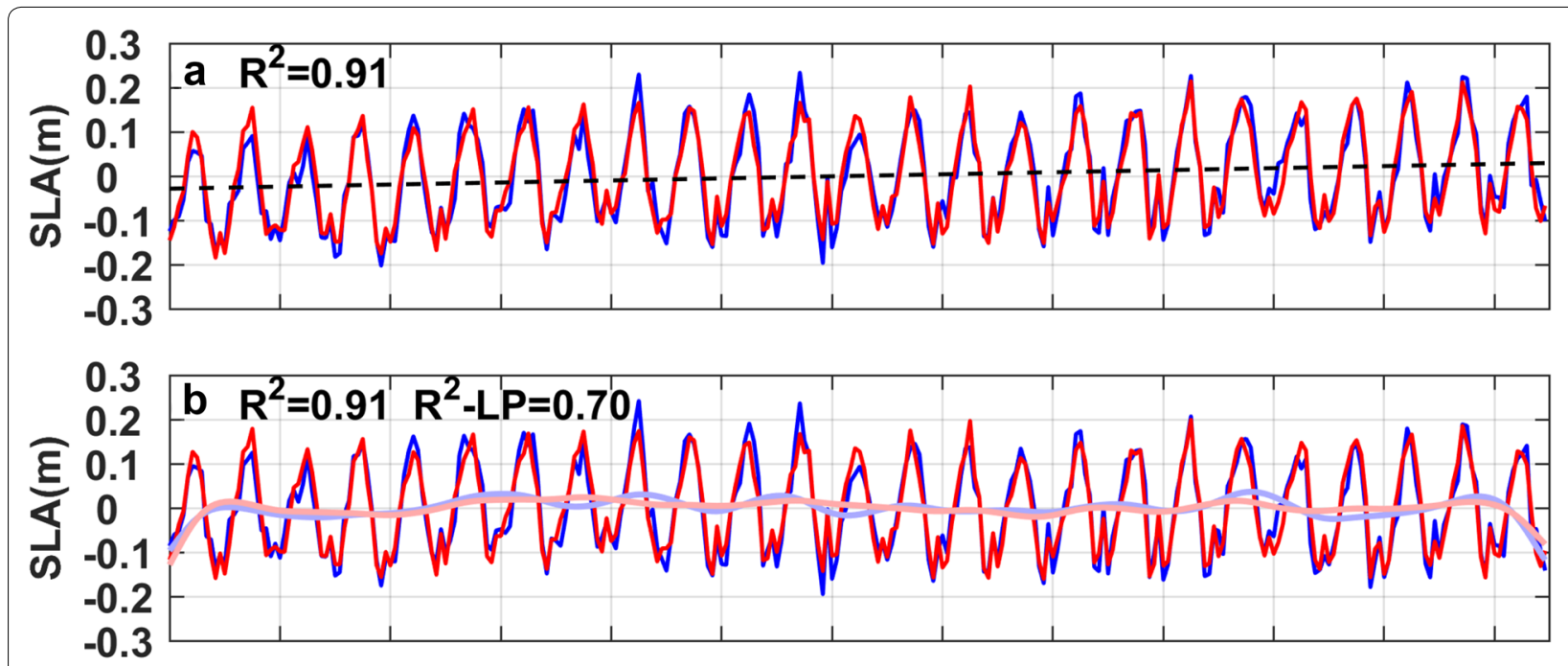

1993199519971999200120032005200720092011201320152017 Time(year)
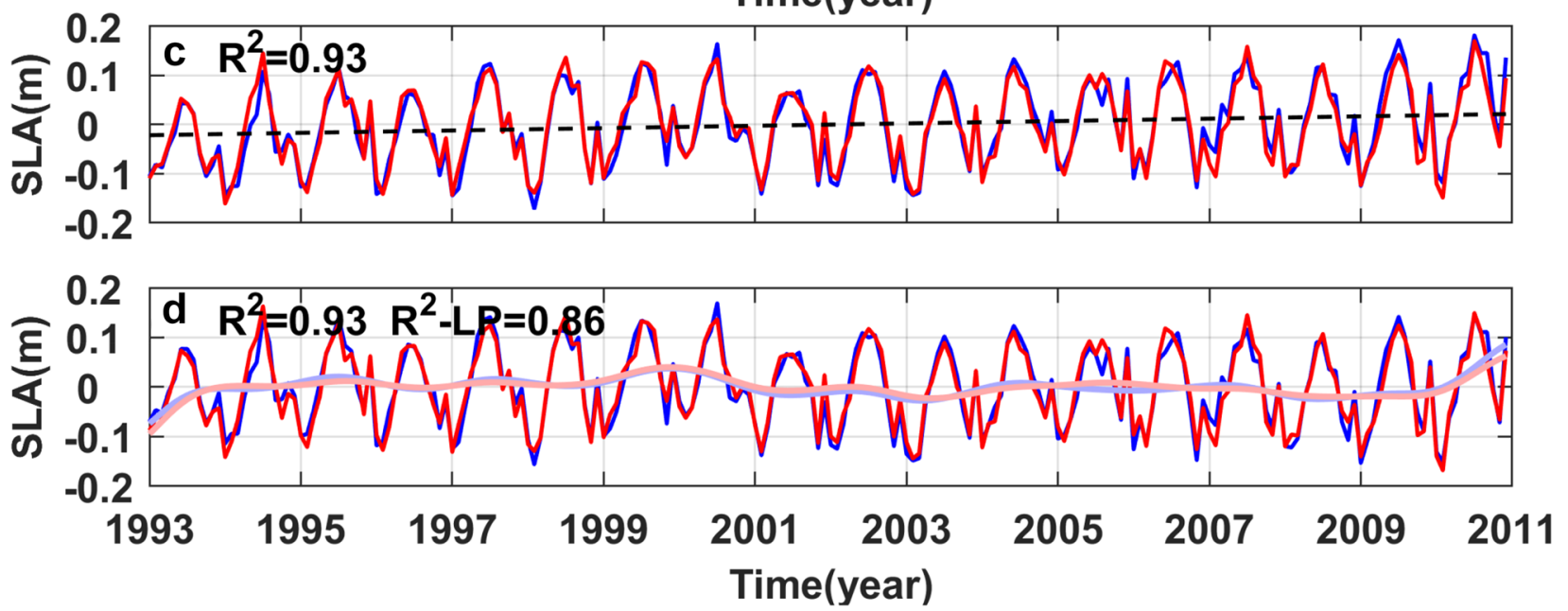

Fig. 6 Comparison of monthly averaged SLA at tide gauge stations (blue) and monthly averaged SLA from Eq. 2 (red) south of KE the jet (a) and north of the KE jet (c), superimposed with the long-term trends (dashed lines). $\mathbf{b}$ and $\mathbf{d}$ are the same as $\mathbf{a}$ and $\mathbf{c}$ with long-term trends removed, superimposed with 1-year low-pass results

North of the KE, similar calculation is conducted. The averaged correlation $\left(R^{2}\right)$ is about 0.50 , again much lower than our estimates (Fig. 7a). The differences in these tide gauge data could also be seen clearly from the time series of SLA at these tide gauge stations (Additional file 1: Figs. S1, S2).

\section{Conclusions and discussion}

From the Minobe et al. (2017) theory and the linear least squares regression, we obtain a polynomial equation to estimate the SL variations along the western boundary of the North Pacific. The estimated SLA accounts for 91\% (93\%) SL variability south (north) of the KE jet. The contributions of SLA ${ }_{0}$, OWA, AWA, SLPA, SSTA, SSSA and KTA to the SL variations on seasonal and longer time scales are quantified. On seasonal time scales, the local thermosteric effect is dominant. On interannual time scales, the signals from ocean and atmospheric forcing are dominant. For decadal SL trends, the $\mathrm{SLA}_{0}$ is dominant, indicating that the coastal SL rise is mainly resulted from the signals from the open ocean. In particular, the long Rossby wave (coastal-trapped waves) is dominant south (north) of the KE jet.

From Fig. 2, it is seen that the sea level variation is very different among different stations, especially for the tide gauges south of the KE. To test whether the results are 


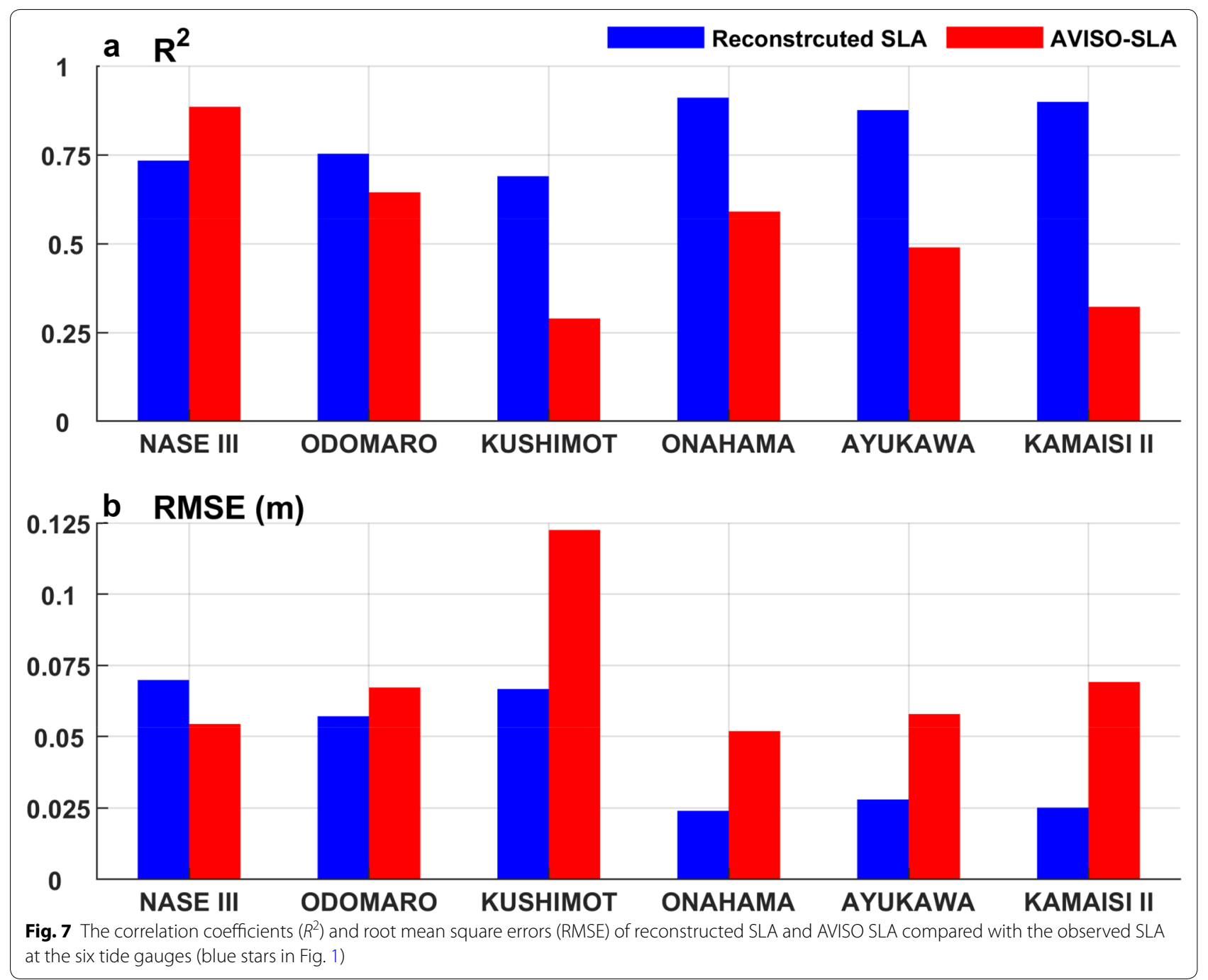

largely affected by the selection of the tide gauges, we randomly pick five out of all the tide gauges south of KE, and do the same regression like Table 2. Six tests were conducted. The results are shown in Additional file 1: Tables S1-S6. We could see that the regression coefficients for each factor are nearly unchanged among all the tests, in accordance with Table 2. This indicated that the signals from ocean interior $(a)$, SLP $(d)$ and thermosteric effect $(e)$ are always on the top three factors affecting SL variations on seasonal time scales. The consistency of these tests illustrates that though the sea level variations are very different among different stations, the effects of the impacting factors remain.

To evaluate the coastal SLA reconstruction with the simple regression method, we compared the reconstructed coastal SLA with the AVISO SLA at six new tide gauge stations. In general, the reconstructed SLA has a better performance than the SLA inferred from AVISO.
It is promising to use the newly derived equation for a better estimate of the coastal SL variations along the western boundary of North Pacific.

\section{Supplementary information}

Supplementary information accompanies this paper at https://doi. org/10.1186/s40562-020-00153-9.

Additional file 1: Tables S1-S6. The same regression conducted as in Table 2. Five out of all the tide gauges south of the KE are selected randomly to estimate the coefficients. Figure S1. The time series of SLA of the three tide gauges south of the KE used for evaluation and the gray lines are the SLAs of the tide gauges used to build the equations. All tide gauge data is 1-year low passed. Figure S2. The same as Fig. S1, but for north of the KE. Figure S3. The time series of SL of tide gauges north of the KE.

\section{Abbreviations}

SL: Sea level; SLA: Sea level anomalies; KE: Kuroshio extension; SLP: Sea level pressure; SST: Sea surface temperature; SSS: Sea surface salinity; OWA: Onshore 
wind anomalies; AWA: Alongshore wind anomalies; SLPA: Sea level pressure anomalies; KTA: Kuroshio transport anomalies; SSTA: Sea surface temperature anomalies; SSSA: Sea surface salinity anomalies.

\section{Acknowledgements}

We thank all of the scientists who collected the oceanographic data used in the study. The work is supported by the National Key R\&D Program of China, No. 2016YFC1401408, and Tsinghua University Initiative Scientific Research Program (2019Z07L01001).

\section{Authors' contributions}

$\mathrm{PL}$ performed the analysis and wrote the initial draft of the paper. FX developed the essential research idea. Both authors contributed to the interpretation of the results and the preparation of the manuscript. Both authors read and approved the final manuscript.

\section{Funding}

National Key R\&D Program of China, No. 2016YFC1401408, and Tsinghua University Initiative Scientific Research Program (2019Z07L01001).

\section{Availability of data and materials}

The tide gauges data used in this study come from the PSMSL (Permanent Service for Mean Sea Level: http://www.psmsl.org). The global SL used in this study is produced by SSALTO/DUACS and downloaded from AVISO (http:// www.aviso.altimetry.fr). The monthly $10-\mathrm{m}$ wind and sea level pressure is obtained from the ERA5 Reanalysis (https://cds.climate.copernicus.eu). The Kuroshio transport is estimated from the Simple Ocean Data Assimilation (SODA3, http://dsrs.atmos.umd.edu/DATA/soda3). The SST and SSS are obtained from EN4 quality-controlled subsurface ocean temperature and salinity profiles (https://www.metoffice.gov.uk/hadobs/en4). The data are available in the aforesaid websites.

\section{Competing interests}

The authors declare that they have no competing interests.

\section{Author details}

${ }^{1}$ Ministry of Education Key Laboratory for Earth System Modeling, and Department of Earth System Science, Tsinghua University, Beijing 100084, China.

2 Southern Marine Science and Engineering Guangdong Laboratory (Zhuhai), Zhuhai 519082, Guangdong, China.

Received: 26 December 2019 Accepted: 17 March 2020 Published online: 30 March 2020

\section{References}

Anthoff D, Nicholls RJ, Tol RSJ, Vafeidis AT (2006) Global and regional exposure to large rises in sea-level: a sensitivity analysis (Tyndell Centre for Climate Change Research working papers, 96) Norwich, UK. Tyndell Centre for Climate Change Research, $31 \mathrm{pp}$

Church JA, Gregory JM, Huybrechts P, Kuhn M, Lam-beck K, Nhuan MT, Qin D, Woodworth PL (2001) Changes in sea level. In: Houghton JT, Ding Y,
Griggs DJ, Noguer M, Van Der Linden PJ, Dai X, Maskell K, Johnson CA (eds) Climate change 2001: The scientific basis. contribution of working group I to the third assessment report of the intergovernmental panel on climate change. Cambridge University Press, Cambridge, pp 639-693

Cipollini F, Oneto L, Coraddu A, Murphy A, Anguita D (2018) Condition-based maintenance of naval propulsion systems with supervised data analysis. Ocean Eng 149:268-278. https://doi.org/10.1016/j.oceaneng.2017.12.002

Cui M, Storch HV, Zorita E (1995) Coastal sea level and the large-scale climate state A downscaling exercise for the Japanese Islands. Tellus A 47(1):13. https://doi.org/10.3402/tellusa.v47i1.11498

Douglas BC (1992) Global sea level acceleration. J Geophys Res 97(C8):1269912706. https://doi.org/10.1029/92JC01133

Ezer T (2019) Analysis of the changing patterns of seasonal flooding along the U.S. East Coast. Ocean Dyn. https://doi.org/10.1007/s10236-019-01326-7

Godfrey JS (1975) On ocean spindown I: a linear experiment. J Phys Oceanogr 5:399-409. https://doi.org/10.1175/1520-0485(1975)005\%3c0399:OOSIA L\%3e2.0.CO;2

Ishii M, Kimoto M, Sakamoto K, Sin-Iti Iwasaki (2006) Steric sea level changes estimated from historical ocean subsurface temperature and salinity analyses. J Oceanogr 62:155-170. https://doi.org/10.1007/s1087 2-006-0041-y

Minobe S, Terada M, Qiu B, Schneider N (2017) Western boundary sea level: a theory, rule of thumb, and application to climate models. J Phys Oceanogr 47:957-977. https://doi.org/10.1175/JPO-D-16-0144.1

Peltier WR (2001) Chapter 4 Global glacial isostatic adjustment and modern instrumental records of relative sea level history. In: International geophysics, vol 75, pp 65-95. https://doi.org/10.1016/s0074-6142(01)80007-3

Qiu B, Chen S, Wu L, Kida S (2015) Wind-versus Eddy-forced regional sea level trends and variability in the North Pacific Ocean. J Clim 28:1561-1577. https://doi.org/10.1175/JCLI-D-14-00479.1

Sasaki YN, Minobe S, Miura Y (2014) Decadal sea-level variability along the coast of Japan in response to ocean circulation changes. J Geophys Res Oceans 119:266-275. https://doi.org/10.1002/2013JC009327

Wang Z, Li J, Chao D, Hu J (2003) Sea level changes detected by using satellite altimeter data and comparing with tide gauge records in China Sea. https://doi.org/10.1007/978-3-642-18861-9_33

Wang H, Liu K, Qi D et al (2016) Causes of seasonal sea level anomalies in the coastal region of the East China Sea. Acta Oceanol Sin 35:21-29. https:// doi.org/10.1007/s13131-016-0825-x

Woodworth PL, Player R (2003) The permanent service for mean sea level: an update to the 21st century. J Coast Res 19:287-295

Yasuda T, Sakurai K (2006) Interdecadal variability of the sea surface height around Japan. Geophys Res Lett. https://doi.org/10.1029/2005GL024920

Zhang Z, Ichikawa K (2005) Influence of the Kuroshio fluctuations on sea level variations along the south coast of Japan. J Oceanogr 61:979-985. https ://doi.org/10.1007/s10872-006-0014-1

\section{Publisher's Note}

Springer Nature remains neutral with regard to jurisdictional claims in published maps and institutional affiliations.

\section{Submit your manuscript to a SpringerOpen ${ }^{\circ}$ journal and benefit from:}

- Convenient online submission

- Rigorous peer review

- Open access: articles freely available online

- High visibility within the field

- Retaining the copyright to your article

Submit your next manuscript at $\boldsymbol{\nabla}$ springeropen.com 